\title{
The Discussion about Qu Yuan Who Used 'ZHEN' to Call Himself from The Songs of Chu of the Warring States
}

\author{
$\mathrm{Hu} \mathrm{Ye}$ \\ School Of Journalism And Communication \\ Xiamen University \\ Xiamen, China \\ Han Ding \\ School of Foreign Language \\ Guilin University of Electronic Technology \\ Guilin, China
}

\author{
Yanmei Zhang \\ School of Foreign Language \\ Guilin University of Electronic Technology \\ Guilin, China \\ College of Liberal Arts \\ South China Normal University \\ Guangzhou, China \\ Lingzhi Zhang* \\ Overseas Education College \\ Xiamen University \\ Xiamen, China \\ *corresponding author
}

\begin{abstract}
This article starts from taking 'ZHEN' as the first exclusive person pronoun from Qu Yuan of The Songs of Chu in the Warring States, indicating that it is not universal to explain that ordinary people could use 'ZHEN' to call themselves though Qu Yuan did. On this basis, the article puts forward different views on 'ordinary person could call himself "ZHEN" before the emperor Qin Shi Huang'. It pointed out that seeing from the existing corpus, with the time periods from oracles of Shang Dynasty to Western Zhou and Spring and Autumn and the Warring States, 'ZHEN' usually served as a claim when the emperor of Shang Dynasty did divination as well as legendary ancient emperors, the emperors of Shang and Zhou emperors talked and gave imperial edict. Though it remained the situation that person except the king used 'ZHEN' to call himself, occasionally 'ZHEN' was utilized by princes, ministers and other nobles.
\end{abstract}

Keywords-the Warring States Period; Qu Yuan; "ZHEN"; the king of the Shang Dynasty; Zhou Emperor; noble

\section{INTRODUCTION}

The first person pronoun appeared in ancient Chinese literatures which have different kinds of statements such as 'wo (我)', 'wu (吾)', 'yu (余)', 'yu (予)', 'ang (印)', 'tai (台)' and 'zhen(朕)'. Among them, 'yu (余)', 'yu (予)', 'wo (我)' and 'zhen (朕)' came into being first where oracles of Shang Dynasty recorded. It is documented in Qin Shi Huang of Shi $J i$ that after China was unified by Qin Shi Huang, he took 'ZHEN' (朕), the first person pronoun, as a claim of emperors. From then on, 'ZHEN' became a salutation of the emperor.
In Classic Chinese (published by Chinese Publishing House, 1999), the author Li Wang pointed out that 'ordinary person could call himself 'ZHEN' before the emperor Qin Shi Huang, and after the reign of Qin Shi Huang, 'ZHEN' became a salutation of the emperor'. In addition, Bojun Yang, Leshi He, Bingjun Zhou, Yujin Zhang and many other experts unexceptionally mentioned that ordinary people could use 'ZHEN' to call themselves during the pre-Qin period in relevant textbooks and works.

Textbooks and works mentioned above wherever refer to the opinion that ordinary person could use 'ZHEN' to call himself before Qin Shi Huang mostly allude the typical use case of using 'ZHEN' as a claim in Li Sao of The Songs of $C h u$ by Qu Yuan without exception.

For instance, it is the book Ancient Chinese Grammar and Its Development (published by Language Publishing House, 2001) by Bojun Yang and Leshi He that took 'no one could hold my tongue' in an ancient poetry $Y i$ in Daya of The Book of Songs and 'the name of my late honored sire bore is Boyong' in Li Sao of The Songs of Chu as examples when mentioned that "ZHEN", generally used in possessive adjectives, is originally the claiming pronoun of ordinary people'.

As another example, Ancient Chinese Grammar written by Yujin Zhang (published by Guangdong Higher Education Press, 2010) said that when 'ordinary people can call himself 'ZHEN' during the pre-Qin Period', it took 'Marquis Han accepted the appointment to Beijing, so Emperor Zhou announced personally that Marquis Han should inherit his ancestors' career and do not live up to expectations' from an ancient poetry Han Yi in Daya of The Book of Songs and 'of 
the god-king Gaoyang, I am the far offspring; the name of my late honored sire bore is Boyong' from $\mathrm{Li}$ Sao of The Songs of Chu as examples.

\section{It DoEs Not Mean That ORdinARy PERSON COULd CALl HimSElF 'ZHEN' WhILE QU YUAN DID}

Then, can ordinary person call himself 'ZHEN' while Qu Yuan used 'ZHEN' as his claim?

We consider that the answer to this question is no.

We can seek out eight examples of the use of 'ZHEN' from The Songs of Chu, including four examples from $\mathrm{Li} \mathrm{Sao}$ of The Songs of Chu, two examples from Jiu Zhang of The Songs of Chu and one example respectively from Zhao Hun of The Songs of Chu and Jiu Tan of The Songs of Chu.

In eight examples, Jiu Zhang of The Songs of Chu and $\mathrm{Li}$ Sao of The Songs of Chu are the works of Qu Yuan. However, there are two versions that the author of Zhao Hun of The Songs of Chu is either Qu Yuan or Song Yu in the same age, with more avocations of Qu Yuan wrote Zhao Hun. Jiu Tan of The Songs of Chu is the work that Liu Xiang in Western Han Dynasty imitated the form of The Songs of Chu.

'ZHEN', the word from six examples from Jiu Zhang of The Songs of Chu and Li Sao of The Songs of Chu written by $\mathrm{Qu}$ Yuan as well as one example from Zhao Hun of The Songs of Chu with a majority of people holding the view that the author is Qu Yuan, are the claim of Qu Yuan himself.

Then, does Qu Yuan who used 'ZHEN' as his claim in The Songs of Chu of the Warring States period is an ordinary person?

From the first sentence of $\mathrm{Li}$ Sao of The Songs of Chu, the poet called himself as the far offspring of the god-king Gaoyang as well as the courtier with the same surname of King Chu. Besides, born in a noble family of Chu State, Qu Yuan had extraordinary literary and political qualities. When in his youth age, Qu Yuan got credit from King Huai of Chu so he became an official as 'Zuo Tu' of the king. It is inferred by Mr. Guo'en You that the occupation of 'Zuo Tu' is second only to the supreme chief executive called 'Ling Yin' of Chu. (Mr. Guo'en You, based on the record that 'Huang Xie, the official "Zuo Tu", was promoted to "Ling Yin" and as a reward, he got the place labeled "Wu" and called Lord of Chunshen' from House of Chu of Historical Records, inferred that 'Zuo Tu' is second only to the supreme chief executive called 'Ling Yin' of Chu. It can be seen from book one of Ancient Chinese Literature whose chief editor is Xingpei Yuan, recorded in page 125, 2005 second edition of Higher Education Press.)

Thus, in examples of The Songs of Chu, we cannot consider that ordinary person could use 'ZHEN' to call himself as Qu Yuan who was not prince did. As in fact Qu Yuan used to be an eminent minister and noble which represented that his identity and status was quite unusual.

\section{Who Could CALL HiMSELF 'ZHEN’ BeFORE QIN SHI HUANG}

Then furtherly, we want to know whether 'ordinary person could call himself 'ZHEN' before Qin Shi Huang in ancient Chinese'?

From our judgement, not ordinary person could call himself 'ZHEN' before Qin Shi Huang. To be more specific, there are mainly several situations that used 'ZHEN' as a claim in pre-Qin period.

\section{A. 'ZHEN' in Oracles of Shang Dynasty Mostly Self- claimed When the Emperor of Shang Dynasty Did Divination}

Concerning the pronoun range of 'ZHEN', The Oracle Inscriptions of Yin Ruins by Mengjia Chen (Science Press, 1956) studying the personal pronoun of oracles once indicated that 'ZHEN' in oracles occasionally is a claim of the emperor of the time, so the emperor usually divines by himself with the word 'ZHEN'. Qing Liu (1998) had opinions in the article The Usage of ' $Z H E N$ ' in Oracle that the scope of reference of 'ZHEN' experienced the process from 'salutation' (the salutation of emperors of Shang Dynasty) to 'general term' (not limited to bronze inscription of Western Zhou to the time before Qin Dynasty established) to 'salutation' ('ZHEN' was drawn up to emperor dedicated in the twenty-sixth year of Qin Shi Huang). That is to say, according to his inspection, 'ZHEN' in oracles are a claim of emperors, so there is no living example of general term and in the oracle ' $\mathrm{Zi} \mathrm{Bu} \mathrm{Ci}$ ' of 'Fei Wang Bu Ci', 'wo (我)' was used to claim oneself, while the king used 'ZHEN' to call himself and person except the king did not use 'ZHEN' for self-claiming. However, according to the opinion that "'ZHEN" is the salutation of emperors' of oracles from Qing Liu (1998), Hong Zhu (2011) had different views that oracle inscriptions of Shang Dynasty had narrow context since participants of divination were only the king of Shang and the person did divination for work. Thus, it is hard to observe 'ZHEN' that addresses to a certain extent comprehensively. But according to the view that 'ZHEN' was mostly used by the king of Shang to do divination in oracles by Mengjia Chen (1956), Hong Zhu held an agreed attitude. In short, seeing from oracles of Shang Dynasty, the sentences that utilizing 'ZHEN' as the first person pronoun are mostly the records of the king of Shang did divination, which receive unanimous approval of experts. We can also clearly see it from plenty of sentences and examples when we observing 'ZHEN' in oracles.

\section{B. Conversations or Imperial Edicts of Ancient Emperors Usually Call Themselves 'ZHEN'}

It often used 'ZHEN' as a claim when the ancient emperors talked and made imperial edict. For example, sentences that legendary Yao and Shun emperors, the emperor of Shang and emperor Zhou that called themselves as 'ZHEN' recorded mostly in pre-Qin documents.

1) Legendary Yao and Shun emperors claimed themselves with 'ZHEN' recorded in Shang Shu: For instance, when old Yao held council of union of tribes, he 
called himself 'ZHEN' discussing abdication of candidates with leaders of each tribe. Emperor Yao said, 'Oh, leaders of princes from all over the world! I have been in my place for seventy years. So can you adapt to my order and carry on my throne?' For another example, Shun claimed himself with 'ZHEN' when appointed $\mathrm{Yi}$ and Long to be his ministers. Emperor Shun talked to Yi, 'All right, then Yi, you take charge of Official Yu.' He talked to Long, 'Long, I hate slander comments and greed behaviors as it will shock my people. I appoint you to be the official of accepting advice, being responsible for conveying my order from morning to night and collecting the views expressed to me. Make sure to convey them truthfully.'

2) The king of Shang used 'ZHEN' to call himself when delivering speeches, making small talk and issuing orders: For example, before Shang Tang crusaded against Xia Jie, he made a mobilization order to his ministers. The emperor Shang said, 'Come on you guys, listen to me, (I do not dare to stage an armed rebellion. Since the emperor Xia of his Country committed many crimes, the god commands me to crusade against him).'For another example, before and after moving the capital, Pan Geng, the king of Shang, command conversations and orders to his relatives, ministers and civilians from three passages narrating from Pan Geng of Shang Shu. Shang Tang and Pan Geng in hese sentences both claimed themselves with 'ZHEN'.

3) Emperor Zhou used 'ZHEN' to call himself when publishing imperial edicts: For instance, about 1046 BC, Jifa destroyed Shang Dynasty and established Western Zhou implementing the system of enfeoffment. King Zhou was the only host of the world known as the emperor. Hence, Emperor Zhou used 'ZHEN' for self-claiming when he made imperial edict.

Another example, during the time of Spring and Autumn and the Warring States, power of emperor Zhou had fallen into the hands of others so that the emperor had no authority to order the world. But he remained the supreme ruler of China in name, using the identity of emperor to publish imperial edict. They all called themselves 'Zhen' when publishing imperial edicts.

\section{Person except the Emperor Claimed Himself with 'ZHEN'}

There are two conditions when person except the king uses 'ZHEN' to call himself. One condition is that shown from the references, besides legendary ancient emperors, the emperors of Shang and Zhou emperors, princes, ministers and other nobles claimed themselves with 'ZHEN'. The other is that Qu Yuan used 'ZHEN' to call himself in The Songs of Chu of the Warring States mentioned in the first and second part of this article.

1) Princes, Ministers and other Nobles used 'ZHEN' as a Claim of Shang, Zhou Dynasty and Spring and Autumn and the Warring States

For instance, Yi Yin, a person in the ancient Chinese prose The Book of Shang of Shang Shu, claimed himself with 'ZHEN'. Duke of Zhou used 'ZHEN' to call himself in Luo Hao of Shang Shu.

For another example, ministers, princes and ladies of princes called themselves ' $\mathrm{ZHEN}$ ' in bronze inscriptions of Western Zhou and Spring and Autumn and the Warring States. During the period of Western Zhou and Spring and Autumn and the Warring States, emperors, princes, ministers and other nobles could utilize the pattern of casting bronze to worship ancestors, commend merits and record important events. When mentioned ancestors of a person, it is common for him to claim himself with 'ZHEN', and that is pronoun acting as the attributive usually uses 'ZHEN', like 'ZHEN Huang Gao Zu' (means 'my glorious emperior'), 'ZHEN Huang Ya Zu' (means 'my honorable grandfather'), 'ZHEN Huang Kao' (means 'my glorious father') and 'ZHEN Huang Zu Kao' (mean 'my honorable ancestor and father').

2) Qu Yuan used 'ZHEN' to Call Himself in The Songs of Chu in the Warring States

As is mentioned before, when it comes to the topic discussed by academic circle that ordinary person could call himself 'ZHEN' before Qin Shi Huang, the experts unexceptionally mentioned the typical example of using 'ZHEN' as a claim in Li Sao of The Songs of Chu by Qu Yuan.

In addition, Hong Zhu (2011) mentioned that the first sentence 'Of the god-king Gaoyang, I am the far offspring; the name of my late honored sire bore is Boyong.' of Li Sao of The Songs of Chu Li Sao of The Songs of Chu by the poet $\mathrm{Qu}$ Yuan of the Warring States, it is an issue puzzles the academic circle of using 'ZHEN' as a claim. She held the view that 'ZHEN' had disappeared from the living language in the time of The Book of Songs. Qu Yuan was simply influenced by $\mathrm{c}$ the expression 'ZHEN + appellation + name' largely exists in inscriptions or some documents of Zhou Dynasty and continued to adopt this language usage pattern.

In fact, eight examples of 'ZHEN' are in The Songs of Chu mentioned above. There are both expression 'ZHEN + appellation + name' and other expressions of 'ZHEN +noun' in eight examples. In addition, there are examples as the subject like '朕 (ZHEN) 幼清以廉洁兮, 身服义而未沫” (means 'when I was a child, I used to possess virtue of integrity, devoting myself to morality and justice without decreasing a bit') in Zhao Hun of The Songs of Chu'.

Thus, it can be said that it was not accidental and not simply follow the language convention of the expression 'ZHEN + appellation + name' largely exists in inscriptions or some documents of Zhou Dynasty for Qu Yuan to call himself 'ZHEN'.

In brief, as described earlier, we consider that it does not mean that ordinary person could call himself 'ZHEN' while $\mathrm{Qu}$ Yuan used 'ZHEN' as his claim.

\section{CONCLUSION}

In short, based on existing corpus, 'ZHEN' usually served as a claim when the emperor of Shang Dynasty did divination as well as legendary ancient emperors, the 
emperors of Shang and Zhou emperors talked and gave imperial edict from the period of oracle to Western Zhou as well as Spring and Autumn and the Warring States. It also remains the situation that 'ZHEN' was utilized by princes, ministers and other nobles, and that is not ordinary person could use 'ZHEN' to call himself before Qin Shi Huang.

Bo Hong (1996) had a similar point that 'ZHEN' mostly used by kings or people of noble rank from oracle and common people generally did not get in touch with it.

However, it is Chinese Pronouns Study on Western Zhou by Yujin Zhang (Chinese Publishing House, 2006) that holds the view that the statement of Bo Hong deserves elaboration as documents record mostly are words and deeds of kings and nobles and none of the documents mention the word of common people so that it is hardly to search for examples used 'ZHEN' by common people.

In addition, Hong Zhu (2011) also thought that because words and historical events related to emperors recorded mostly in ancient Chinese documents, speakers largely were emperors and a small number of ministers and it is rare to see common people's words record in documents, it restricted the perception of people nowadays to the term ' $\mathrm{ZHEN}$ ' that addresses to a certain extent.

We hold reservations on the opinion that due to nobody record or rarely record the words of common people, it is hard to find out common people used 'ZHEN' as a claim. The reason is that it is truly hard to find out examples that common people called themselves ' $Z$ HEN' in ancient times.

When it comes to "ZHEN" is originally a general claim of oneslf' mentioned from Ancient Chinese Outline written by Bingjun Zhou (published by Hunan Education Press, 1981), it quoted Dogmatism from Cai Yi that namely "ZHEN" equals to "me". People of higher rank and lower rank can use it in ancient times. Hence, "ZHEN" had the same meaning to two types of people mentioned above. In the twenty-sixth year of Qin Shi Huang on the throne, he established "ZHEN" as the claim of emperor so that it had remained in the later ages.'

There are two understandings to 'people of higher rank and lower rank can use "ZHEN" in ancient times' in Dogmatism from Cai Yi. One understanding is that ordinary people could also use it as a claim while the other is apart from emperors, princes, ministers and nobles could also use 'ZHEN' to call themselves (common people generally did not use it). We consider that the latter one more reasonable, and that is 'ZHEN' is not exclusive to emperors but not ordinary people have the choice to use it. At least looking from the existing literature, no counter-example can be found.

In conclusion, we hold different views on the opinion 'ordinary person could call himself ' $\mathrm{ZHEN}$ ' before the emperor Qin Shi Huang', and that is not ordinary person could call himself 'ZHEN' before Qin Shi Huang. It was especially mentioned that when it comes to why the emperor Qin Shi Huang took 'ZHEN' as the first exclusive person pronoun of the emperors from the written article 'Why the Emperor Qin Shi Huang Took "ZHEN" as the First Exclusive Person Pronoun of the Emperors' (ICCESSH
2016), it can be said that using 'ZHEN' as a claim after the unity of China by Qin Shi Huang is a continuation to the ancient emperors, the king of the Shang Dynasty and Zhou Emperor.

\section{ACKNOWLEDGEMENT}

This research was financially supported by Fujian Social Science Planning Fund Program \& Annual key projects of China Special Socialism Theory System Research Center in Fujian (2012B237).

\section{REFERENCES}

[1] Li Wang (Chief Editor). Classic Chinese (Revised Edition) (four books) [M]. Beijing: Chinese Publishing House, 1999.

[2] Bojun Yang, Leshi He. Ancient Chinese Grammar and Its Development [M]. Beijing: Language Publishing House, 2001.

[3] Bingjun Zhou. Ancient Chinese Outline [M]. Changsha: Hunan Education Press, 1981.

[4] Yujin Zhang. Grammar Study on Ancient Chinese. Guangzhou: Guangdong Higher Education Press, 2010.

[5] Yujin Zhang. A Research on Chinese Pronoun of the Western Zhou Dynasty [M]. Beijing: Zhong Hua Book Company, 2006.

[6] Qing Liu. The Usage of Oracle 'ZHEN' [J]. Journal of Chongqing Teachers College, 1998 (01).

[7] Mengjia Chen. The Review of Divination Inscriptions of Yin Ruins [M]. Beijing: The Science Publishing Company, 1956.

[8] Hong zhu. The Function of Denotation and Pragmatics of the First Person Pronoun 'ZHEN' in Ancient Chinese [J]. Journal of Bohai University (philosophy and social science edition), 2011(05).

[9] Xingpei Yuan (Chief Editor). History of Chinese Literature (the second edition) (four books) (book one) [M]. Beijing: Higher Education Press, 2005.

[10] Bo Hong. Differences of the First Person Pronoun 'yu (余/予)' 'wo (我) 'zhen (朕)' in Ancient Chinese [J]. The Study of Language, 1996 (01).

[11] Yanmei Zhang. The Syntactic Function of the First Person Pronoun "ZHEN" in Ancient Chinese. [J]. Modern Chinese (Language Research Edition), 2016, 06.

[12] Yanmei Zhang. et al. 2016. "Why the Emperor Qin Shi Huang Took 'ZHEN' as the First Exclusive Person Pronoun of the Emperors" 2016 International Conference on Contemporary Education, Social Sciences and Humanities (ICCESSH 2016), St. Petersburg, Russia, Sept. 27-28, 2016. Paris, France: Atlantis Press, Electronic product451-453 pp. 